\title{
Low-temperature complete oxidation of BTX on Pt/activated carbon catalysts
}

\author{
Jeffrey Chi-Sheng Wu*, Zhi-An Lin, Feng-Ming Tsai, Jen-Wei Pan \\ Department of Chemical Engineering, National Taiwan University, Taipei, Taiwan 10617, ROC
}

\begin{abstract}
The catalytic destruction of volatile organic compound (VOC) benefits from a low oxidation temperature due to less energy consumption. In this study, activated carbon-supported Pt catalysts were prepared for benzene, toluene and xylene (BTX) deep oxidation at below $200^{\circ} \mathrm{C}$. Activated carbon can serve as a media for concentrating VOC. The carbon supports were heated to 400 or $800^{\circ} \mathrm{C}$ under $\mathrm{N}_{2}$ flow and washed with $\mathrm{HF}$ acid to remove surface impurities and/or minerals. The $\sim 0.3 \mathrm{wt} . \%$ $\mathrm{Pt} /$ activated carbon catalysts were prepared by the incipient wetness method, followed by $\mathrm{H}_{2}$ reduction at $300^{\circ} \mathrm{C}$ for $2 \mathrm{~h}$. The catalytic oxidation was conducted with a BTX concentration ranging from 640 to $2000 \mathrm{ppmv}$ in air at volume hour space velocity (VHSV) of approximately $21000 \mathrm{~h}^{-1}$. The light-off curves were very steep and the light-off temperatures ranged between 130 and $150^{\circ} \mathrm{C}$, well below those of the $\mathrm{Pt} / \mathrm{Al}_{2} \mathrm{O}_{3}$ catalyst. The oxidation activity was promoted because of a higher surface BTX concentration due to the adsorption capability of activated carbons. Moisture reduces the activity only slightly due to the hydrophobicity of activated carbon. Generally, the Pt catalysts with thermally-treated activated carbon had lower ignition temperatures. Experimental results indicated that high-temperature pretreatment of activated carbon could effectively increase the catalyst activity. Meanwhile, X-ray photoelectron spectroscopy (XPS)/secondary ion mass spectroscopy (SIMS) investigation revealed that the graphitized surface might play a role in catalytic activity. Finally, this work suggested a reaction mechanism based on the adsorption-migration of hydrocarbons to reveal the enhanced activity of activated carbon support. (C) 2000 Elsevier Science B.V. All rights reserved.
\end{abstract}

Keywords: BTX; Catalytic oxidation; Pt; Activated carbon; VOC

\section{Introduction}

Volatile organic compound (VOC) is a major air pollutant. The complete combustion of VOC can be costly because a high temperature must be maintained which often requires supplemental fuel. The advantage of low oxidation temperature is reduced fuel consumption particularly for large volumes of diluted VOC polluted air. Catalytic oxidation can effectively destruct VOC in air to meet stringent environmental regula-

* Corresponding author. Tel.: +886-2-363-1994; fax: +886-2-362-3040.

E-mail address: cswu@ccms.ntu.edu.tw (J.C.-S. Wu). tions. Supported Pt alumina and other metal oxides are traditional catalysts for such applications and have received wide attention [1]. However, at a low temperature, the water vapor generated by VOC oxidation can be easily condensed in the micro/meso pores due to the hydrophilicity of oxide supports. Furthermore, the influence of moisture on catalytic activity cannot be ignored.

The deep oxidation of benzene on $\mathrm{Pd} / \mathrm{Y}$ zeolite was found to decrease significantly with saturated water at a low temperature $(533 \mathrm{~K})$, while no adverse water effect existed at a higher one [2]. Despite the unclear reason for the negative water effect, the catalyst might be cloaked and the activity was reduced. 
Additionally, ambient air usually contains moisture. The activity of catalysts may shift under various humidities. The oxidation of methane on $\mathrm{Pd} / \mathrm{Al}_{2} \mathrm{O}_{3}$ was inhibited significantly under moist conditions while no influence existed with unsupported Pd catalysts [3]. This phenomenon implies that the water accumulation on the $\mathrm{Al}_{2} \mathrm{O}_{3}$ support could be the major cause of the deactivation of $\mathrm{Pd}$. Hydrophobic supports would avoid such problems. Chuang et al. [4,5] compared the oxidation of several VOC compounds (aromatics, methanol, and formaldehyde) over Pt hydrophilic and hydrophobic catalysts, and found complete oxidation could be achieved at much lower temperatures using hydrophobic supports. Meanwhile, Drago et al. [6] reported that low temperature deep oxidation of VOC was achievable using carbonaceous material, such as ambersorb $^{\circledR}$.

Activated carbon is widely applied as an adsorbent to remove VOC [7]. Catalyst-impregnated activated carbon can serve as media for concentrating VOC prior to oxidizing them in situ, without oxidizing the base carbon [8]. The concentration of locally adsorbed hydrocarbons can be higher than that of the gas phase, thus enhancing oxidation activity. Earlier investigation indicated that the complete oxidation of benzene, toluene and xylene (BTX) could be achieved on the hydrophobic Pt catalysts at lower temperature [9]. The surface characteristics of the catalyst can be important in the catalytic activity. This work investigates BTX oxidation in various Pt/activated carbons, which are pretreated thermally and chemically.

\section{Experimental}

Activated carbon $\left(\right.$ Darco $\left.^{\circledR}\right)$ was purchased from Aldrich, crushed, then sieved to 80 mesh. Carbon powder was heated at 400 or $800^{\circ} \mathrm{C}$ under $\mathrm{N}_{2}$ stream for $1 \mathrm{~h}$ to remove adsorbed contaminants before use (assigned as AC400 and AC800). The activated carbon used in this study was found to contain minerals (mostly silica and alumina) according to energy dispersive X-ray spectroscopy (EDS) analysis [9]. Part of the activated carbon (AC800) was rinsed further with $40 \% \mathrm{HF}$ for $24 \mathrm{~h}$ to reduce mineral content, then thoroughly washed with de-ionized water and dried at room temperature (assigned as $\mathrm{AC} 800 \mathrm{HF})$.
Platinum catalysts were prepared via the incipient wetness method aiming for $0.3 \mathrm{wt} . \% \mathrm{Pt}$ (assigned as Pt/AC400, Pt/AC800 and Pt/AC800HF). Precursor salt, $\mathrm{H}_{2} \mathrm{PtCl}_{6} \cdot x \mathrm{H}_{2} \mathrm{O}$, was purchased from Aldrich with $\sim 40$ wt. $\%$ of platinum. Methanol was chosen as the diluting solvent for better soaking of the activated carbon. The quantity of methanol required to completely fill the pore volume of activated carbon was predetermined. An amount of methanol-soluble Pt solution used for the impregnation was often from 95 to $100 \%$ of the adsorptive capacity of the activated carbon. The concentration of the Pt solution was such that the amount of elemental $\mathrm{Pt}$ in the solution absorbed on the activated carbon was equal to a desired 0.3 wt. $\%$. Following impregnation, the catalysts were dried at ambient temperature overnight. All the catalysts were then reduced at $300^{\circ} \mathrm{C}$ for $1 \mathrm{~h}$ with $3^{\circ} \mathrm{C} / \mathrm{min}$ rising from room temperature under $20 \% \mathrm{H}_{2} / \mathrm{N}_{2}$ flow, then stored in a desiccator for later use. The precise $\mathrm{Pt}$ loading of the catalysts was measured using the wet chemical method. The Pt/activated carbon catalyst was weighed, then transferred to a crucible and burned in an air-circulated furnace at $800^{\circ} \mathrm{C}$ for $6 \mathrm{~h}$. The remaining ash was stirred and dissolved in aqua regia. The solution was filtered and diluted with deionized water to the appropriate concentration. A series of standard Pt solutions (Aldrich) were employed to establish calibration curves. The Pt concentration of solution was measured by UV adsorption at $261.8 \mathrm{~nm}$ [10], then the percentage weight of Pt loading was calculated. A batch of $0.3 \mathrm{wt} . \% \mathrm{Pt} / \mathrm{Al}_{2} \mathrm{O}_{3}$ was also prepared through the above method for comparison.

BTX were purchased from Alps and used directly. Xylene is a mixture of ortho, meta and para isomers. Fig. 1 depicts the schematic of reactor system. An air stream bubbling through a saturator filled with liquid hydrocarbon carried an individual vapor (BTX). The concentrations ranged from 640 to $2000 \mathrm{ppmv}$, as regulated by the temperature of the saturator and mixed with another air stream. The concentration was always confirmed by GC before the experiment. The water vapor could be carried by another saturator filled with water, and mixed with reactant stream. The reactions were performed at temperatures ranging from 90 to $210^{\circ} \mathrm{C}$ under atmospheric pressure. The catalyst $(0.25-0.5 \mathrm{~g})$ was charged in the middle of a straight-tube Pyrex reactor with 16-mm ID. A thermocouple was placed in the center of the catalyst 


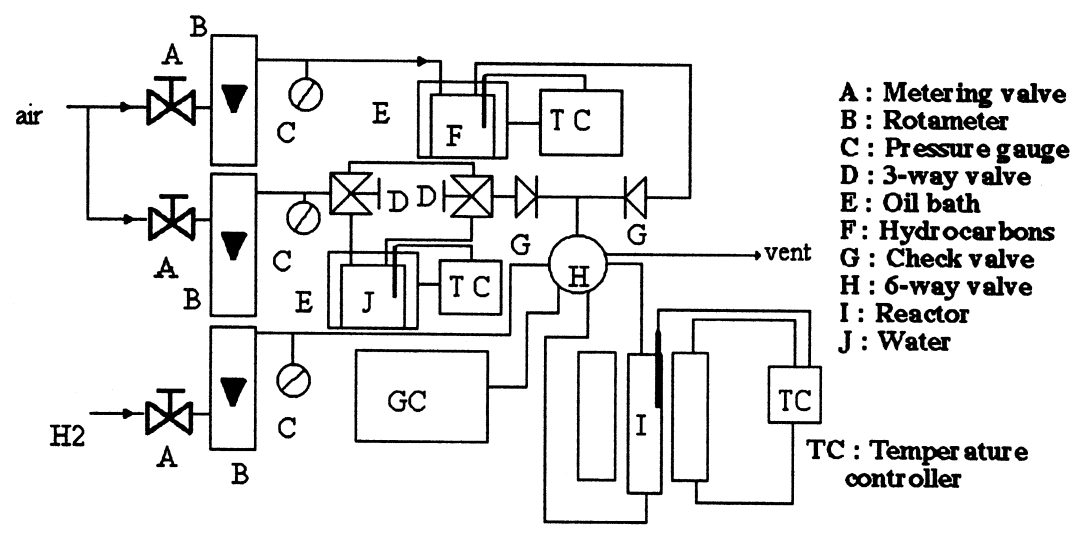

Fig. 1. Schematic of reactor system.

bed to record reaction temperature and also to control the furnace. The catalyst was heated to $300^{\circ} \mathrm{C}$ for $1 \mathrm{~h}$ then cooled to room temperature in air before switching to reactant stream. The reactant flows were tuned to a VHSV (volume hour space velocity) of 16000-23000 $\mathrm{h}^{-1}$. The reactant flow rate was reduced correspondingly for $\mathrm{Pt} / \mathrm{Al}_{2} \mathrm{O}_{3}$ to maintain the same VHSV since alumina was denser than activated carbon. The reaction temperature usually increased from low to high, and decreased to low temperature in some cases to check consistency. Typically, an accumulated run time was $\sim 30 \mathrm{~h}$ per catalyst. Both reactants and products were measured by an on-line GC. The primary products found were $\mathrm{CO}_{2}$ and $\mathrm{H}_{2} \mathrm{O}$ only. Other hydrocarbon by-products were virtually undetectable under most experimental conditions. Thus, the conversion was calculated based on hydrocarbon consumption. A blank test was conducted with activated carbon without Pt loading. No activity was observed below $250^{\circ} \mathrm{C}$.

The specific surface area of activated carbon was calculated from the result of $\mathrm{N}_{2}$ adsorption using the BET equation. The particle size of $\mathrm{Pt}$ on catalysts was inspected through X-ray diffraction (XRD). The adsorptions of benzene (or toluene, xylene) on activated carbon were measured from the weight loss up to $360^{\circ} \mathrm{C}$ via thermogravimetric analysis (TGA). Activated carbon was immersed in benzene (or toluene, $\mathrm{xy}$ lene) liquid for $24 \mathrm{~h}$. Excess surface liquid was wiped off before the TGA experiment. The surface characteristics of the activated carbon was studied by secondary ion mass spectroscopy (SIMS) and X-ray pho- toelectron spectroscopy (XPS). SIMS and XPS were conducted on the MicroTech MT500. The spectrometer vacuum was in the $10^{-9}$ torr range for XPS measurement. The hemispherical analyzer was operated in the fixed retarded ratio near $11 . \mathrm{Mg} \mathrm{K} \alpha$ radiation ( $h v=1253.6 \mathrm{eV})$ was used as X-ray source. For SIMS analysis, $\mathrm{Ar}^{+}$ion gun was used. A quadrupole mass sepectrometer measured the secondary ions.

\section{Results and discussion}

\subsection{Characteristics of activated carbon}

Table 1 lists the specific surface areas of various activated carbons. The specific surface areas increase following thermal and HF treatments. Both thermal and $\mathrm{HF}$ washing effectively increase surface area due to the cleansing surface. The surface area of $\mathrm{AC} 800 \mathrm{HF}$ gives the highest surface area, possibly due to mineral removal opening pores. After benzene oxidation reaction, the specific surface areas of the catalysts were

Table 1

Specific surface area of Pt catalyst

\begin{tabular}{lll}
\hline Specific area $\left(\mathrm{m}^{2} / \mathrm{g}\right)$ & Fresh catalyst & After benzene oxidation \\
\hline Pt/AC400 & 484 & 352 \\
Pt/AC800 & 530 & 302 \\
Pt/AC800HF & 743 & 570
\end{tabular}

${ }^{\mathrm{a}}$ Benzene oxidation: $2000 \mathrm{ppmv}$ in air. 


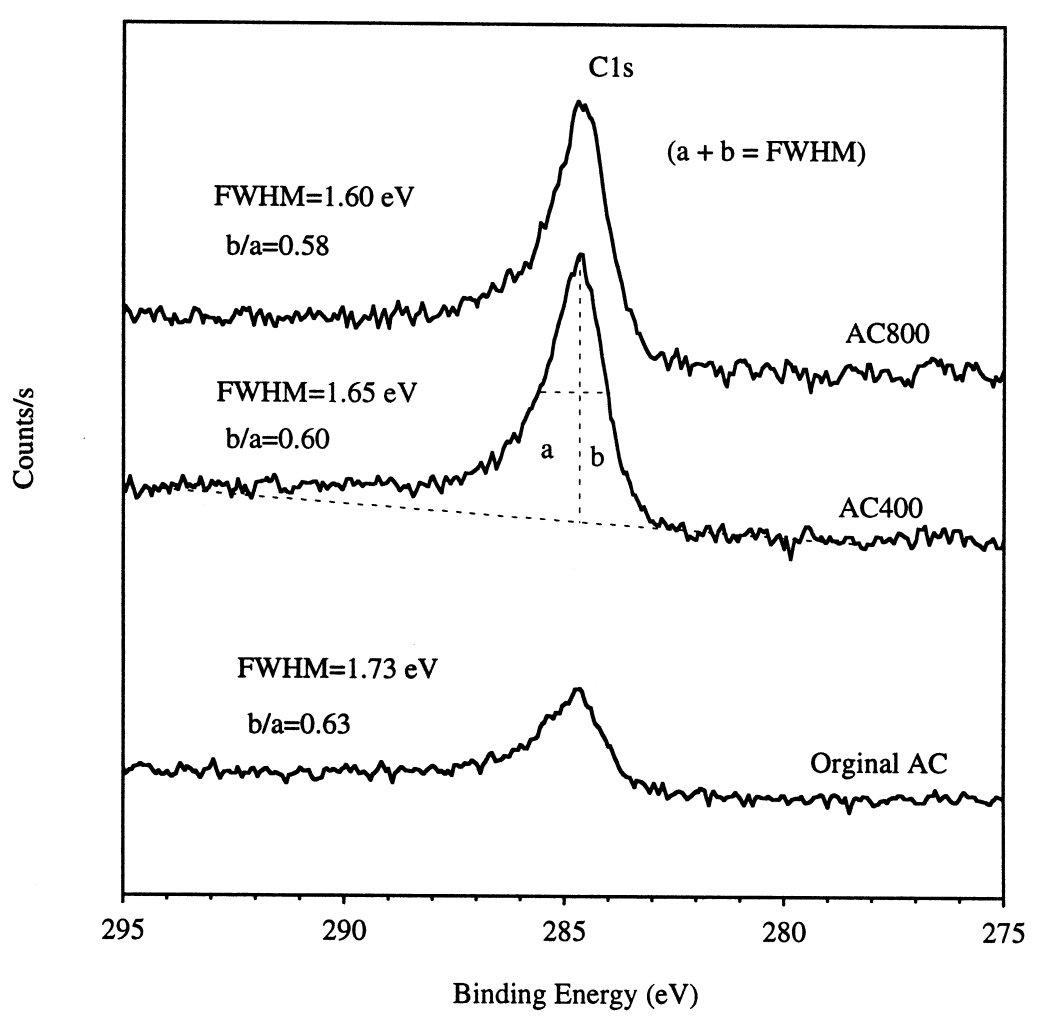

Fig. 2. XPS C 1s spectra of active carbons with various thermal treatment (FWHM: full width at half maximum).

reduced $20-40 \%$. The reduction of surface area might be due to the coking of benzene or burning of activated carbons.

The surface characteristics of activated carbon are crucial to the adsorption and catalytic properties. The microstructure of activated carbon comprises of a cross-linked aromatic sheet with graphite or structured carbons scattered on surfaces randomly [11]. Micropores are the space of slitted sheets. Fig. 2 presents the $\mathrm{C} 1 \mathrm{~s}$ spectra of three activated carbons from XPS measurement. Unlike XRD or Raman, XPS is capable of providing structural information on the outmost surface of several Angstrom depths. Takahagi and Ishitani [12] and Albers et al. [13] reported that graphite exhibited highly asymmetric $\mathrm{C} 1 \mathrm{~s}$ peaks while amorphous carbon gave symmetric peaks. Additionally, amorphous carbon gave broad C 1s peak while narrow peak in graphite. In Fig. 2, the asymmetric coefficients (ratio of $b / a$ ) change from 0.63 (original activated carbon) to 0.60 (AC400) and 0.58
(AC800) indicating the extent of surface graphitization. Thermal treatment makes the surface of AC800 and AC400 partially graphitized or at least partially structured carbon. For HF treated activated carbon, the XPS peak is very similar to that of thermal treated one. Obviously HF treatment did not change the microstructure of activated carbon. Fig. 3 displays the negative ion SIMS of original activated carbon, $\mathrm{AC} 400$ and $\mathrm{AC} 800$, respectively. The ion ratio of negative ion fragments also indicates the microstructure of surface carbon. The ratio of $\mathrm{CH}^{-} / \mathrm{C}_{2} \mathrm{H}^{-}$correlates to the extent of surface graphitization. The smaller the ratio, the higher the graphiticity or the more structured carbon $[13,14]$. In Fig. 3 , the ratio of $\mathrm{CH}^{-} / \mathrm{C}_{2} \mathrm{H}^{-}$ is 0.73 in the original activated carbon, and declines to 0.25 and 0.38 in $\mathrm{AC} 400$ and $\mathrm{AC} 800$, respectively. This is additional evidence suggesting the surface partially graphitized by thermal treatment. The graphitized surface contains benzene-ring structure, and thus abundant $\pi$ electrons. The $\pi$ electron can 

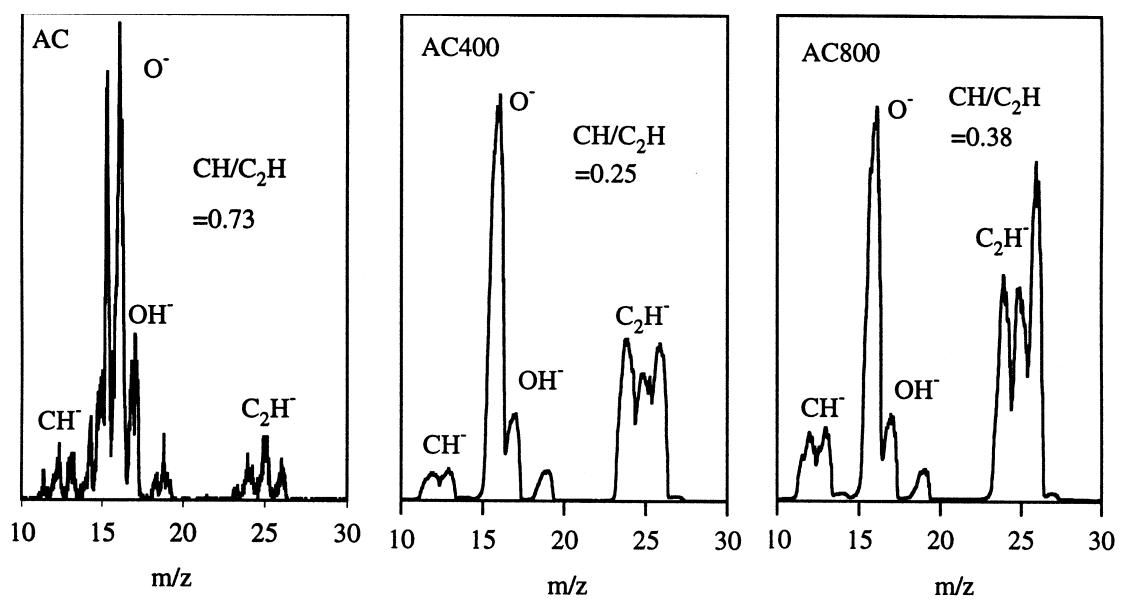

Fig. 3. Negative ion SIMS of active carbons.

offer the enhanced affinity of aromatics, particularly benzene.

Table 2 presents the adsorption of BTX on four supports. The quantity of uptake is the total desorption from room temperature to $360^{\circ} \mathrm{C}$ of benzene, toluene and xylene, respectively. Above $400^{\circ} \mathrm{C}$, other impurities may possibly desorb/evaporate, since AC400 is only pretreated at $400^{\circ} \mathrm{C}$. Despite AC 800 being pretreated at higher temperatures, for comparison on the same basis, the termination temperature is set at $360^{\circ} \mathrm{C}$. The amounts of BTX adsorption on $\gamma-\mathrm{Al}_{2} \mathrm{O}_{3}$ are significantly below those of activated carbon because of the hydrophilic surface. Meanwhile, the $\pi$ sites of partially graphitized activated carbon may also influence BTX adsorption. The quantities of adsorption correlates well to the specific areas of the activated carbons (Table 1). AC800HF has the highest capacity for BTX adsorption. This support was thermally pretreated at $800^{\circ} \mathrm{C}$ as well as $\mathrm{HF}$ was washed so that large surface available for BTX absorption.

Table 2

Total adsorption amount ${ }^{\mathrm{a}}$ of BTX on active carbons and $\gamma-\mathrm{Al}_{2} \mathrm{O}_{3}$

\begin{tabular}{lccc}
\hline & Benzene $(\mathrm{g} / \mathrm{g})$ & Toluene $(\mathrm{g} / \mathrm{g})$ & Xylene $(\mathrm{g} / \mathrm{g})$ \\
\hline $\mathrm{AC} 800 \mathrm{HF}$ & 0.180 & 0.161 & 0.153 \\
$\mathrm{AC} 800$ & 0.139 & 0.135 & 0.103 \\
$\mathrm{AC} 400$ & 0.125 & 0.137 & 0.099 \\
$\gamma-\mathrm{Al}_{2} \mathrm{O}_{3}$ & $\sim 0.009$ & $\sim 0.010$ & $\sim 0.004$ \\
\hline
\end{tabular}

${ }^{a}$ The amount of adsorption is determined from the desorption in TGA, temperature: room temperature to $360^{\circ} \mathrm{C}$.

\subsection{Characteristics of Pt/activated carbon catalysts}

Table 3 lists the measured Pt loadings of catalysts, which range from 0.20 to 0.29 wt. $\%$. Metal loadings are approximately what they are aimed for $0.3 \mathrm{wt} . \%$. The weight percentages of $\mathrm{Pt}$ remained practically unchanged after oxidation reaction indicating a negligible Pt loss. Static hydrogen chemisorption was attempted to measure the dispersion of Pt. However, no reliable data could be obtained, possibly due to the strong hydrogen adsorption of activated carbon. This study believes that the Pt clusters are very small because no Pt particle can be observed on the TEM micrographs of catalysts up to 200000 magnification. Meanwhile, XRD measurement of catalysts shows that no spectra display $\mathrm{Pt}$ peaks at $2 \theta=39.5^{\circ}$ (the strongest peak of Pt crystalline) before and after BTX oxidation, indicating the most Pt particles are smaller than $3 \mathrm{~nm}$. Therefore $\mathrm{Pt}$ is fairly well dispersed, and the sintering of $\mathrm{Pt}$ appears minimal due to low reaction

Table 3

Metal loading of Pt catalysts

\begin{tabular}{lll}
\hline Catalysts & Fresh (wt.\%) & After reaction (wt.\%) \\
\hline Pt/AC400 & 0.25 & 0.23 \\
Pt/AC800 & 0.29 & 0.25 \\
Pt/AC800HF & 0.20 & 0.22 \\
\hline
\end{tabular}

a 640 ppm benzene reaction: Pt/active carbon disolved in, and Pt solution measured by UV adsorption at $261.8 \mathrm{~nm}$ [10]. 
temperature. Coloma et al. [15] also reported that the Pt dispersion would stabilize when the surface carbon was pregraphitized due to the $\pi$ sites of basal planes. Thus, the variations of $\mathrm{Pt}$ dispersion among these catalysts can be ruled out. The catalytic activity of $\mathrm{Pt}$ is intrinsically similar among all the above catalysts.

\subsection{Deep oxidation of BTX}

Fig. 4 shows the oxidation of benzene ( $640 \mathrm{ppmv})$ on various catalysts. High oxidation activity was observed on Pt/activated carbons catalysts. The temperature of complete oxidation was $\sim 200^{\circ} \mathrm{C}$ for $\mathrm{Pt} / \mathrm{Al}_{2} \mathrm{O}_{3}$ while the temperatures were in the range $140-180^{\circ} \mathrm{C}$ for Pt/activated carbon catalysts. Furthermore, the light-off curves were very steep for Pt/activated carbon catalysts. Their light-off temperatures (at ca. $50 \%$ conversion) occurred at 132 and $140^{\circ} \mathrm{C}$ on $\mathrm{Pt} / \mathrm{AC} 800$ and $\mathrm{Pt} / \mathrm{AC} 800 \mathrm{HF}$, respectively. The light-off temperature of Pt/AC400 approaches that of $\mathrm{Pt} / \mathrm{Al}_{2} \mathrm{O}_{3}$. However, the complete oxidation temperature of $\mathrm{Pt} / \mathrm{AC} 400$ is, $180^{\circ} \mathrm{C}$, lower than that of $\mathrm{Pt} / \mathrm{Al}_{2} \mathrm{O}_{3} . \mathrm{Pt} / \mathrm{AC} 800$ gives the highest activity among the Pt/activated carbon catalysts as it shows the lowest light-off temperature. The surface concentration

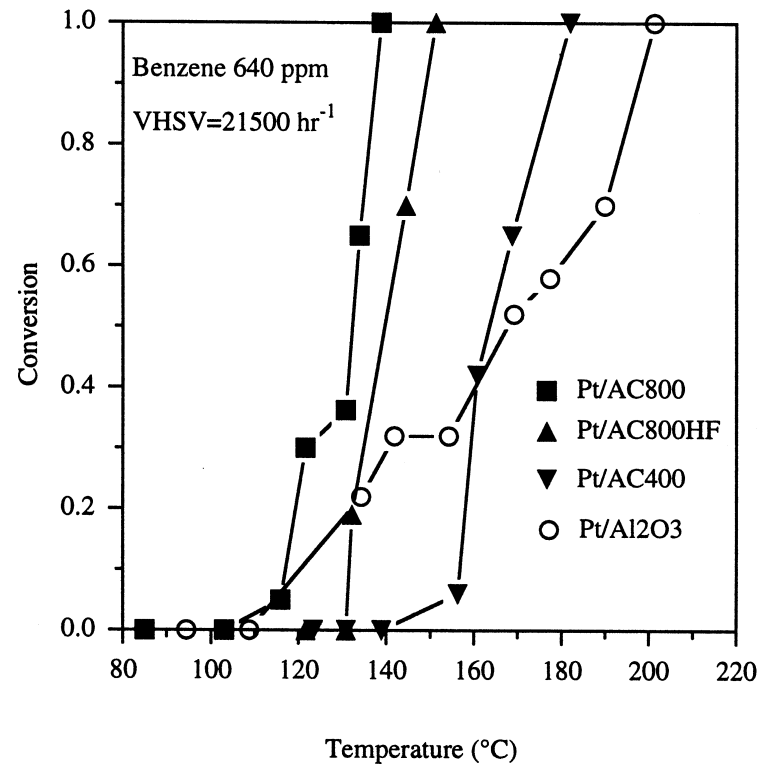

Fig. 4. The comparison of benzene oxidation on various Pt catalysts. of benzene on the catalyst would be the major factor of activity. The adsorptions of BTX on $\gamma-\mathrm{Al}_{2} \mathrm{O}_{3}$ are well below those of activated carbons resulting the lowest oxidation activity. However, the activity of $\mathrm{Pt} / \mathrm{AC} 800 \mathrm{HF}$ is lower than that of thermally-treated Pt/AC800, though the quantities of benzene adsorption are reversed. The mineral content of AC800HF is removed by an HF wash. The hydrophobicity of $\mathrm{Pt} / \mathrm{AC} 800 \mathrm{HF}$ could increase slightly while the weak surface acidity may be reduced [16]. The intermediates of oxidation could be influenced by the catalyst acidity causing the variation of the activity. The positive effect of thermal treatment might be counteracted by the surface acidity decrease on Pt/AC $800 \mathrm{HF}$.

Fig. 5 shows the oxidations of BTX with a concentration of 2000 ppmv on Pt/AC800. The oxidation of benzene gives the lowest light-off temperature, followed by toluene and xylene. Generally, the combustion of paraffins is more difficult than that of aromatics [17]. Meanwhile, aromatics associated with the methyl groups are more difficult to oxidize than benzene [18]. Our results are consistent with those in literature. The order of BTX activity also follows the order of adsorption of BTX (Table 2) indicating that the oxidation rate is correlated to surface BTX concentration. The light-off temperature of benzene at 2000 ppmv is ca.

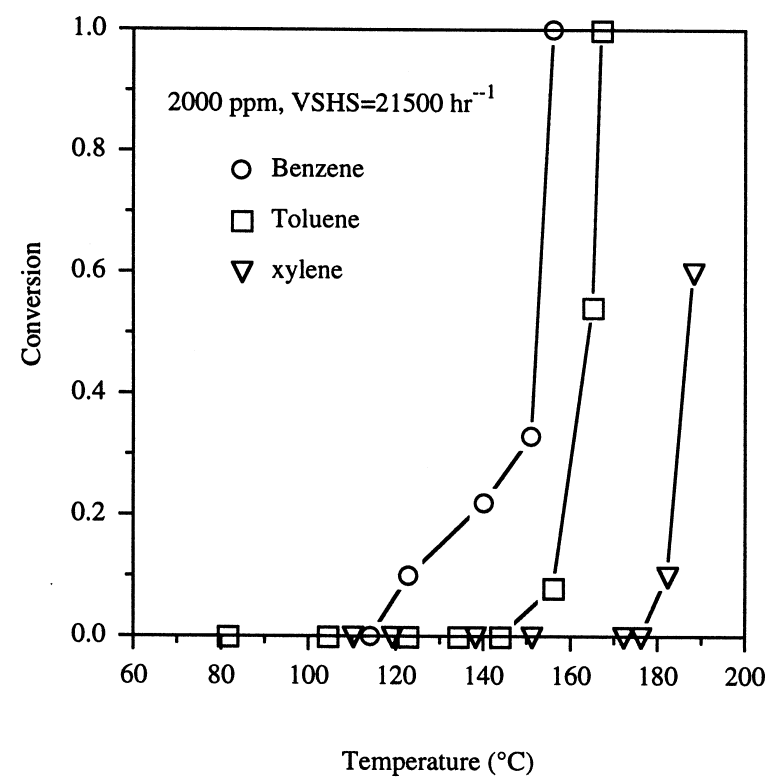

Fig. 5. BTX deep oxidation on Pt/AC800 catalyst. 
Table 4

Reaction (light-off) temperature of cal. 50\% conversion oxidation ${ }^{\mathrm{a}}\left(640 \mathrm{ppm}, \mathrm{VHSV}=21500 \mathrm{~h}^{-1}\right)$

\begin{tabular}{|c|c|c|c|c|c|c|}
\hline \multirow[t]{2}{*}{ Catalysts } & \multicolumn{2}{|l|}{ Benzene } & \multicolumn{2}{|l|}{ Toluene } & \multicolumn{2}{|l|}{ Xylene } \\
\hline & Dry $\left({ }^{\circ} \mathrm{C}\right)$ & $6 \%$ water $\left({ }^{\circ} \mathrm{C}\right)^{\mathrm{b}}$ & Dry $\left({ }^{\circ} \mathrm{C}\right)$ & $6 \%$ water $\left({ }^{\circ} \mathrm{C}\right)$ & Dry $\left({ }^{\circ} \mathrm{C}\right)$ & $6 \%$ water $\left({ }^{\circ} \mathrm{C}\right)$ \\
\hline $\mathrm{Pt} / \mathrm{AC} 400$ & 167 & 176 & 183 & 170 & 164 & 163 \\
\hline $\mathrm{Pt} / \mathrm{AC} 800$ & 131 & 151 & 157 & 166 & 169 & 172 \\
\hline $\mathrm{Pt} / \mathrm{AC} 800 \mathrm{HF}$ & 137 & 154 & 148 & 172 & - & 174 \\
\hline $\mathrm{Pt} / \mathrm{Al}_{2} \mathrm{O}_{3}$ & 170 & - & - & - & - & - \\
\hline
\end{tabular}

a $50 \%$ conversions by interpolation oxidation curves.

${ }^{\mathrm{b}}$ Benzene concentration is 1000 ppmv.

$143^{\circ} \mathrm{C}$, higher than ca. $130^{\circ} \mathrm{C}$ at $640 \mathrm{ppmv}$ (Fig. 4). Such a phenomenon is normal for VOC oxidation using Pt catalysts, i.e., the lower the concentration the lower the light-off temperature [19].

\subsection{Water effect}

As well known, moisture greatly influences VOC oxidation in most situations, especially at low temperatures. Table 4 summarizes the light-off temperatures of ca. $50 \%$ conversion of BTX oxidation with/without the influence of $6 \%$ water in the feed. Generally, the activities of Pt/AC 800 and Pt/AC800HF are better than those of Pt/AC400 since the former light-off temperatures are lower. Overall, the light-off temperatures increased slightly with moisture in feed, except for toluene oxidation in Pt/AC400. However, the temperature difference is not significant, indicating similar activities are obtainable under both dry and humid conditions. The influence of water is two-fold, including the masking effect on Pt sites, and the adsorption or condensation on supports. The former may still influence the activity regardless of supports. The later can be minimized on hydrophobic supports. The results indicate that activity of $\mathrm{Pt} /$ activated carbon is only slightly influenced by moisture because of negligible water adsorption or condensation of activated carbon. The influence of moisture on $\mathrm{Pt} / \mathrm{AC} 800 \mathrm{HF}$ is expected to be less since the surface mineral is removed. However, its activity still resembles that of Pt/AC800. The reason for this phenomenon may be the same as mentioned above, that is the reduction of weak acid sites. For Pt/AC400, the light-off temperatures of toluene oxidation in dry feed are higher than those in 6\% water condition. The reason for this phenomenon is unclear.

\subsection{Stability of catalysts}

The stability of Pt/activated carbon is critical in applications because carbon could be burned off in air. Fig. 6 shows the life test of Pt/AC800. The total toluene oxidation of $\mathrm{Pt} / \mathrm{AC} 800$ was carried out continuously with a concentration of $640 \mathrm{ppmv}$ at $\sim 165^{\circ} \mathrm{C}$ for more than $80 \mathrm{~h}$. The bed height of the catalyst was visually almost unchanged after the reaction. Low temperature could be the main reason for activated carbon surviving longer under such oxidizing conditions. Additionally, the surface of AC800 is partially graphitized so that it is more resistant to air oxidation [15].

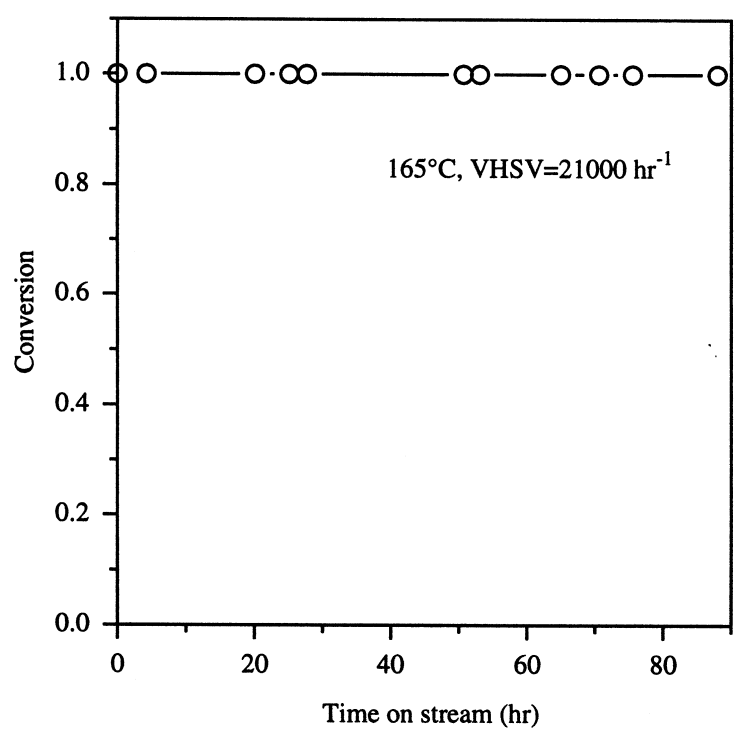

Fig. 6. The long term test of $\mathrm{Pt} / \mathrm{AC} 800$ of toluene oxidation at concentration $640 \mathrm{ppm}$. 


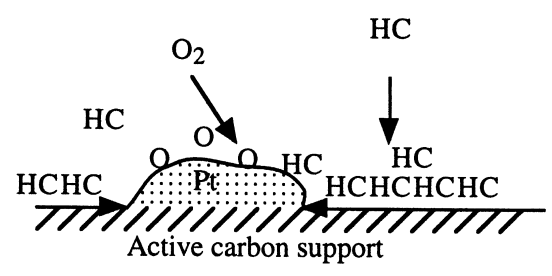

Fig. 7. Illustration of surface migration of VOC oxidation on active carbon.

\subsection{A proposed mechanism}

Fig. 7 proposes and illustrates a possible reaction route for the oxidation of BTX on the surface of Pt/activated carbon catalyst. Hydrocarbon (HC) can be adsorbed on both $\mathrm{Pt}$ and activated carbon, but more on activated carbon since it offers a much larger surface area than Pt clusters do. The competition adsorption of $\mathrm{O}_{2}$ and hydrocarbons on $\mathrm{Pt}$ affects the ignition temperature. In the lean fuel condition, the surface of $\mathrm{Pt}$ is covered by $\mathrm{O}_{2}$ because the sticking coefficient of $\mathrm{O}_{2}$ exceeds that of hydrocarbon [19]. A redox cycle occurs on Pt activated sites. Pt is oxidized and becomes $\mathrm{Pt}-\mathrm{O}$ waiting to be reduced by hydrocarbon. Adsorbed hydrocarbons migrates and is oxidized on the $\mathrm{Pt}-\mathrm{O}$ activated sites due to the concentration gradient around the Pt. The ability of hydrocarbon adsorption and migration on surface thus becomes important factors, and can influence the overall oxidation activity. Water may cover the catalyst surface but its effect is minimized due to hydrophobic support. Therefore, the catalyst activity could be enhanced by increasing hydrocarbon adsorption/migration through the support pretreatment of Pt/activated carbon catalysts.

\section{Conclusions}

This study demonstrates the enhancement of total oxidation of BTX on Pt/activated carbon catalysts at a low temperature range. Energy can be saved when combusting VOC by using such catalysts. The activity was only slightly influenced by moisture due to the hydrophobic surface of the activated carbons.
Thermally-treated Pt/activated carbon promoted the oxidation activity because of the increased BTX adsorption and migration. Meanwhile, the surface characteristics of activated carbon are important in the oxidation activity. Activated carbon was fairly durable under low oxidation temperature. The catalysts have potential applications to remedy VOC pollution.

\section{Acknowledgements}

The authors would like to thank the National Science Council, Taiwan, Republic of China for financially supporting this research under Contract No. NSC-88-2214-E-002-028.

\section{References}

[1] J.J. Spivey, Ind. Eng. Chem. Res. 26 (1987) 2165.

[2] L. Becker, H. Förster, Appl. Catal. B 17 (1998) 43.

[3] C.F. Cullis, B.M. Willatt, J. Catal. 83 (1983) 267.

[4] K.T. Chuang, S. Cheng, S. Tong, Ind. Eng. Chem. Res. 31 (1992) 2466.

[5] K.T. Chuang, B. Zhou, S. Tong, Ind. Eng. Chem. Res. 33 (1994) 1680.

[6] R.S. Dargo, K. Jurczyk, D. Singh, V. Young, Appl. Catal. B 6 (1995) 155.

[7] S. Sircar, T.C. Golden, M.B. Rao, Carbon 34 (1) (1996) 1.

[8] J.N. Nwankwo, A. Turk, Environ. Sci. Technol. 9 (9) (1975) 846.

[9] J.C.S. Wu, T.Y. Chang, Catal. Today 44 (104) (1998) 111.

[10] C. Prado-Burguete, A. Linares-Solano, F. Rodríguez-Reinoso, C. Salinas-Martínez De Lecea, J. Catal. 128 (1991) 397.

[11] R.C. Bansal, J.-B. Donnet, F.S. Stoeckli, Active Carbon, Marcel Dekker, New York, 1988 (Chapters 1-3).

[12] T. Takahagi, A. Ishitani, Carbon 26 (3) (1988) 389.

[13] P. Albers, K. Seibold, G. Prescher, H. Müller, Appl. Catal. A 176 (1999) 135.

[14] P. Albers, K. Deller, B.M. Despeyroux, G. Prescher, A. Schäfer, K. Seibold, J. Catal. 150 (1994) 368.

[15] F. Coloma, A. Sepúlveda-Escribano, J.L.G. Fierro, F. Rodríguez-Reinoso, Langmuir 10 (1994) 750.

[16] A.Yu. Lukomskaya, I.A. Tarkovskaya, G.M. Tel'biz, Kinet. Catal., part 231 (2) (1990) 436.

[17] W. Chu, H. Windawi, Chem. Eng. Prog. 92 (3) (1996) 37.

[18] A.A. Barresi, G. Baldi, Ind. Eng. Chem. Res. 33 (1994) 2964.

[19] G. Veser, M. Ziauddin, L.D. Schmidt, Catal. Today 47 (1999) 219. 